\title{
Spatial and Temporal Variability of Heat, Water Vapor, Carbon Dioxide, and Momentum Air-Sea Exchange in a Coastal Environment
}

\author{
Timothy L. Crawford, Robert T. McMillen, Tilden P. Meyers, and Bruce B. Hicks ${ }^{1}$ \\ National Oceanic and Atmospheric Administration, Air Resources Laboratory, Atmospheric Turbulence and Diffusion Division, \\ Oak Ridge, Tennessee
}

\begin{abstract}
The spatial and temporal variability of heat, moisture, momentum, and $\mathrm{CO}_{2}$ turbulent fluxes in a coastal environment were assessed using simultaneous eddy correlation measurements from a tower, a boat, and an aircraft platform. The flux measurements were made using new instrument systems, including new $\mathrm{CO}_{2}$ and $\mathrm{H}_{2} \mathrm{O}$ sensors, low-flow distortion packages, and careful sensor motion correction systems. The flux tower was operated on the windward beach of Florida's Bahia Honda Key, while the boat was stationed upwind between 1 and $15 \mathrm{~km}$ offshore. The airplane flew transects 10 to $20 \mathrm{~m}$ above the ocean surface, along flight paths extending from the tower to $40 \mathrm{~km}$ offshore. Dissolved $\mathrm{CO}_{2}$ in the coastal waters and atmospheric $\mathrm{CO}_{2}$ concentrations were continuously measured throughout the experiment. The results indicate good agreement among the different sensing systems and demonstrate that air-to-sea trace gas, momentum, and energy flux density measurements are achievable from both a boat and an aircraft. Further, the observations emphasize the complex temporal and spatial trends possible in a coastal region. Due to the nonequilibrated boundary layer, generated by spatial trends, nearshore measurements are not representative of either the entire coastal region or of the open ocean. The observed $10 \mathrm{~W} \mathrm{~m}^{-2}$ sensible heat flux was time-invariant but did vary spatially with surface temperature, which was strongly correlated with ocean depth. The 100 to $200 \mathrm{~W}$ $\mathrm{m}^{-2}$ evaporative moisture flux dominated energy exchange and varied both in space and in time. No consistent diurnal variation was observed, but the spatial trend also followed surface temperature. As expected, momentum flux scaled with wind speed. $\mathrm{CO}_{2}$ exchange showed large spatial and temporal variance. Spatially, the surface temperature warmed as the shore was approached and $\mathrm{CO}_{2}$ was apparently driven off. Temporally, $\mathrm{CO}_{2}$ exchange varied greatly, as did $\Delta p \mathrm{CO}_{2}$ which ranged from +50 to $-100 \mathrm{ppm}$. This large variability in $\Delta p \mathrm{CO}_{2}$ is thought to illustrate the importance of biological and physical processes and to explain the large $\mathrm{CO}_{2}$ fluxes observed (not always in the same direction) in this and other flux studies in nearshore conditions. Ten kilometers from shore, where the spatial and temporal variability was less, $\mathrm{CO}_{2}$ transfer velocities were of the order of $0.1 \mathrm{~cm} \mathrm{~s}^{-1}$.
\end{abstract}

\section{INTRODUCTION}

Energy and $\mathrm{CO}_{2}$ exchange between the atmosphere and the diverse land surface and vast ocean systems has become a controversial issue important to understanding future climate scenarios. Air-sea exchange, which largely determines the global budgets of many trace gases and energy, has become the basis of a growing list of research initiatives. Development of instrument systems capable of accurately measuring air-sea exchange is critical to the success of these programs [e.g., Lenschow and Hicks, 1989]. Accurate landbased air-surface exchange measurement techniques have now become routine and robust. Only recently, with newly available instrumentation and careful application, has it become possible to extend this capability with confidence to open ocean trace gas, momentum, and energy exchanges [Bradley et al., 1991; Tsukamoto et al., 1990; Denmead, 1991].

Because of past measurement limitations, air-sea $\mathrm{CO}_{2}$, momentum, and energy exchange estimates have been based on inferential bulk transfer methods. Their "calibration" depends on limited intensive field studies involving the use of gradient methods or tower-based eddy correlation techniques. The history of these intensive measurements is long.

\footnotetext{
IAlso at National Oceanic and Atmospheric Administration, Air Resources Laboratory, Silver Spring, Maryland.

This paper is not subject to U.S. copyright. Published in 1993 by the American Geophysical Union.

Paper number 93JD00628.
}

The reader is referred to papers by Slinn et al. [1978], Papadimitrakis et al. [1986], Wu [1988], and Asher and Pankow [1991], and references therein, for a cross section of relevant information. Various models have been developed to describe the exchange; some of the most comprehensive discussions of the water vapor, heat, and momentum cases are by Hicks [1972], Garratt [1977], $W u$ [1982, 1986, 1988], and Smith [1988].

It must be emphasized that there is a key difference between air-sea exchange models depending on the nature of the data used to represent the ocean. Some models use bulk ocean data, such as would be obtained from a ship's engine intake several meters below the surface. Others, which limit the complexity of the exchange process by explaining the transfer in the air alone, require surface film conditions such as infrared surface temperature for sensible $(H)$ and latent energy $(L E)$ flux densities. These two approaches lead to substantially different expressions, depending upon what is assumed to be the appropriate controlling quantity representing the ocean. The common factor is the way in which the surface thermal film enters the scenario (see Hasse [1971], Hicks [1975], Wesely [1980], and Coppin et al. [1991]; and for extension to other quantities, see Deacon [1977] and Liss and Merlivat [1986]).

Even in the best understood cases for heat, water vapor, and momentum there is still considerable uncertainty in the ocean bulk transfer parameterizations. This may also, in part, help explain the lack of carbon and energy closure in current global budget estimates. In the case of $\mathrm{CO}_{2}$ exchange, these uncertainties are especially severe. Global 
budgets and exchange rates are largely based on ${ }^{14} \mathrm{C}$ studies [see Toggweiler et al., 1989a, b]. Regional exchange rates are mostly inferred from radon studies. In the absence of direct methods for measuring $\mathrm{CO}_{2}$ fluxes, techniques based on these ${ }^{14} \mathrm{C}$ and radon study results have become well accepted [see Broecker and Peng, 1982]. However, at smaller scales, accumulating evidence indicates that local variability may be high [e.g., Asher and Pankow, 1990; Watson et al., 1991], possibly due to causes associated with surface films and ocean currents.

Coastal regions, the transition between the continents and the open oceans, are physically and biologically complex environments for air-sea exchange measurements in which spatial and temporal variability of exchange rates are expected to be high. Physically, these highly dynamic environments are characterized by large temperature gradients, developing boundary layers, tides, currents, and local land or sea breeze circulations that transport energy between and through the air and the ocean systems. Air-sea turbulent exchange processes are further modulated in space and time by breaking waves, air bubble entrainment, temperaturedependent viscosity, the presence or absence of capillary wavelets, and surface films. Moreover, the shallow, nutrient-rich coastal waters are biologically intensely productive. Within the water column, photosynthesis and respiration couple the production and consumption of oxygen and carbon dioxide. Reefs add additional complexity to the air-sea exchange process by influencing the carbon cycle, waves, currents, and microlayer surface films. Such factors and their interactions make the coastal region a challenging environment for flux measurements and interpretation.

With the physical and chemical processes varying in both space and time, caution must be exercised when interpreting the representativeness of measurements made at a point in a coastal environment. Spatial and temporal variability (as addressed, for example, by Smith and Jones [1986]) are manifested in the development of a nonuniform concentration field. This leads to horizontal (and sometimes vertical) advective transport, which places doubt on the representativeness of point measurements. Further, if temporal or horizontal transport terms are important, then classical one-dimensional equilibrium theories, both bulk parameterizations and similarity models, do not apply. For experimental convenience, most "ocean" $\mathrm{CO}_{2}$ exchange measurements have been made from shore-based towers [Smith and Jones, 1986; Wesely et al., 1982; Smith et al., 1991]. Although such measured fluxes are correct for a small upwind sea surface region (or 'footprint"), considerable uncertainty exists in the representativeness of these measurements [Wesely et al., 1986]. Confidence in observed coastal region point flux measurements could be obtained by measuring horizontal and vertical concentration gradients. Concentration and flux transects from moving platforms are necessary to assess the spatial heterogeneity of air-sea exchange rates of heat, momentum, and $\mathrm{CO}_{2}$, and the representativeness of single point measurements.

Recent sensor technology advances have allowed the development of a low-cost instrument system referred to as the mobile flux platform (MFP), described in detail by Crawford et al. [1990, 1991]. The system has been designed for high-fidelity flux measurement on any moving platform for which flow distortion is minimized. Heat, momentum, moisture, and $\mathrm{CO}_{2}$ flux densities between the atmosphere and the sea surface were measured simultaneously from a shore-based tower and from MFP systems deployed on boat and aircraft platforms in a coastal region near the Florida Keys. The results illustrate the spatial and temporal complexity of the coastal marine environment and verified our mobile measurement procedures for marine applications.

\section{EXPERIMENTAL Procedures}

\subsection{Eddy Correlation Method}

There are several micrometeorological techniques available to measure turbulent fluxes [Businger, 1986; Baldocchi et al., 1988; Lenschow and Hicks, 1989], but the eddy correlation method is the only one that provides a direct flux measurement. The desirability of the technique is further enhanced because of its short time scale and noninvasive nature. Observations using a 15 -min time scale permit the process studies needed to improve predictive capability. Since the flux measurement is made above the surface without disturbing the surface itself, it cannot influence the result. Further, from any measurement platform the flux measurement represents an integrated spatial average of the air-surface exchange rate from a spatially limited upwind footprint [Leclerc and Thurtell, 1990; Schuepp et al., 1990]. From stationary platforms the temporal flux variability is easily assessed from continuous measurements. In contrast, fast moving platforms such as airplanes are well suited to assess the spatial variability of turbulent fluxes.

Application of the eddy correlation method requires fast response instrumentation to measure the wind vector and the scalars of interest. For the tower and boat system reported here, a $10-\mathrm{Hz}$ sonic anemometer measured the wind vector and virtual temperature [Kaimal et al., 1990]. On the airplane a $40-\mathrm{Hz}$ pressure sphere anemometer described by Crawford and Dobosy [1992] was used. Fast response (15 $\mathrm{Hz}) \mathrm{H}_{2} \mathrm{O}$ and $\mathrm{CO}_{2}$ flux density measurements were made with an open path infrared absorption gas analyzer [Auble and Meyers, 1992]. This new generation analyzer was specifically designed for $\mathrm{CO}_{2}$ flux measurements. A small but detectable negative water vapor interference in the $\mathrm{CO}_{2}$ channel was characterized as $-0.06 \mathrm{mg} \mathrm{CO}_{2}$ per $\mathrm{g} \mathrm{H}_{2} \mathrm{O}$. This means that a $200 \mathrm{~W} \mathrm{~m}^{-2}$ latent heat flux would introduce a $\mathrm{CO}_{2}$ flux contamination of $-0.004 \mathrm{mg} \mathrm{m}^{-2} \mathrm{~s}^{-1}$. This interference, 3 orders of magnitude below our observed $\mathrm{CO}_{2}$ fluxes, does not pose any problem for interpretation of the results reported later.

Based on $\mathrm{CO}_{2}$ exchange estimates from methodologies that average over long time and large space scales, Broecker et al. [1986] suggested a flux detection sensitivity target of $\pm 0.01 \mathrm{mg} \mathrm{m}^{-2} \mathrm{~s}^{-1}$. This target is unnecessarily restrictive for the fast, small-scale eddy correlation technique, which operates over smaller time and space scales. At small space and time scales, fluxes can be much greater than the largerscale average. Since these fluxes are often not consistently of the same sign, averaging these fluxes over space and time will lead to low net fluxes. Unfortunately, Broecker's suggested detection target was the premise for much of the criticism of eddy correlation results in a coastal region [see Wesely 1986]. Inspection of the results presented here reveals that the measured fluxes were always well above this target, although it is recognized that coastal regions repre- 
sent a biologically unique environment different than open ocean.

With the eddy correlation method, vertical turbulent flux densities are determined following Webb et al. [1980], as

$$
F_{s} \equiv \overline{(\rho w)^{\prime} s^{\prime}}=\overline{(\rho w) s}-\overline{(\rho w)} \bar{s}
$$

where the overbars denote a time average quantity, and the primed quantities indicate an instantaneous deviation from the average values. Here, $\rho$ is the dry air density, $w$ is the vertical velocity component, and $s$ is temperature for heat flux or the mass mixing ratio with respect to dry air for $\mathrm{H}_{2} \mathrm{O}$, $\mathrm{CO}_{2}$, or any other trace gas constituent of interest. For the tower and boat systems an averaging period of $30 \mathrm{~min}$ was used to obtain statistically robust flux measurements. In contrast, airplanes fly through turbulent atmospheric structures at more than 10 times the rate that such structures advect past a tower. Therefore with the "frozen turbulence" hypothesis, a 3-min airplane data covariance is equivalent to the 30-min tower covariance. For homogeneous flat sites a 30 -min tower time series is long enough to obtain a mean vertical velocity $(\bar{w})$ approaching zero.

The covariance of $(\rho w)^{\prime}$ with the measured concentration fluctuations $s^{\prime}$ represents a turbulent flux that is normal to the mean wind streamlines or surface. For experimental locations that are not perfectly flat, such as our island tower location, $\bar{w}$ is not necessarily zero because the wind streamlines approximately follow the surface. However, the anemometer coordinate system was mathematically rotated to obtain a zero mean vertical and transverse velocity component $(\bar{w}=\bar{v}=0)$. This rotation is only possible with three-dimensional air velocity sensors (i.e., sensors which measure all three wind components). The rotation also corrects for anemometer mounting alignment errors and gives a turbulent flux which is normal to the local wind streamline. Conceptually similar but mathematically more complex rotations are applied during processing of MFP data.

\subsection{Tower Eddy Correlation Measurements}

The sonic anemometer and $\mathrm{CO}_{2}$ sensor were mounted atop a $10-\mathrm{m}$ tower that was located on land $15 \mathrm{~m}$ from the shoreline. The tower mounting system and sensors were carefully designed to minimize flow distortion. The signals from the flux instrumentation were interrogated at $20 \mathrm{~Hz}$. The data were graphically displayed in real time for periodic visual inspection. All raw data were written to portable storage media for additional postprocessing. The computer and data storage devices were housed in an air-conditioned van during the experiment. Other standard meteorological measurements made at the tower included mean wind speed and direction, incoming solar radiation, air temperature, and relative humidity. These instruments were sampled at $1 \mathrm{~Hz}$ and averages were determined every $30 \mathrm{~min}$.

\subsection{Boat and Airplane Eddy Correlation Measurements}

Eddy correlation measurement from a moving platform requires that the wind sensor velocity, $\mathbf{v}_{\mathbf{p}}$, be accurately measured and removed from the measured relative wind velocity, $\mathbf{v}_{\mathbf{a}}$. Given these two velocity vectors in an Earthfixed coordinate system which is accurate from low to high frequencies, the ambient wind vector is obtained as

$$
\mathbf{V}=\mathbf{v}_{\mathbf{p}}+\mathbf{V}_{\mathbf{a}}
$$

The MFP is a direct approach to obtaining the $\mathbf{V}_{p}+\mathbf{V}_{\mathrm{a}}$ vector sum regardless of the support platform.

The complete three-dimensional rotational and translational freedom of the sensors and flow distortion of the $V_{a}$ vector are the primary difficulties of the MFP measurement. Both $\mathbf{V}_{\mathrm{a}}$ and $\mathbf{V}_{\mathrm{p}}$ are necessarily measured in coordinates relative to the moving sensors. Thus sensor observations must be transformed (rotated) to fixed Earth coordinates. As usual, $\mathbf{V}_{\mathrm{a}}$ must be measured in a flow region undisturbed by the vehicle carrying the sensors. This requires a boom to position the sensors into undisturbed flow. Unfortunately, booms also amplify platform-induced sensor motion in proportion to boom length and the magnitude of platform rotation. Thus the advantage of the MFP's design for direct measurement of sensor velocity becomes apparent.

In the past, eddy correlation measurement from mobile platforms has usually been limited to expensive instrumentation permanently installed on dedicated research aircraft. This traditional aircraft approach uses an inertial navigation system (INS) to determine airplane motion, from which boommounted sensor motion is computed. Though well proven, the INS approach is expensive and requires significant space and electrical power, limiting its application to larger platforms. Larger platforms increase flow distortion problems, restrict flexibility, and increase cost. However, low-power modern microcomputers and improved sensors now allow for simple, more streamlined flux measurement systems.

In both the traditional INS approach and the present approach, sensor velocity $\mathbf{V}_{p}$ is determined by integration of the three measured acceleration components. An additional complication of the INS approach is that the accelerometers are not collocated with the $\mathbf{V}_{\mathbf{a}}$ sensors; therefore tangential and centripetal accelerations relative to the INS must be computed. This computation assumes 'stiff" geometric mounting (i.e., no boom vibrations) and accurate measurements of rotational velocity and acceleration. However, unlike the INS accelerometers, the MFP accelerometers are collocated with the $\mathrm{V}_{\mathrm{a}}$ sensors and are continually changing orientation relative to the Earth. Therefore each acceleration measurement must be rotated to Earth coordinates before integrating. Since integration compounds any error over time, it is necessary to mix an accurate low-frequency velocity measurement during integration. This technique retains important high-frequency sensor-velocity information, while suppressing erroneous velocity drift. The thirdorder scheme, employed in each coordinate direction, is similar to that suggested by Blanchard [1971] for vertical velocity.

The method for measuring $V_{a}$ relative to the sensors, while simultaneously minimizing flow disturbances caused by the platforms, is dictated by aerodynamics. For the low-speed boat a sonic anemometer was used. For the higher-speed airplane, a nine-hole pressure sphere gust and heat flux probe was developed [Crawford and Dobosy, 1992]. The probe design also allowed collocated static pressure and temperature sensors. This design places four static pressure ports directly on the sphere and permits temperature measurement within the central pressure port. The temperature measurement is thus in a region of controlled flow disturbance. Although both the airplane and the boat platforms were specifically selected to minimize flow distor- 


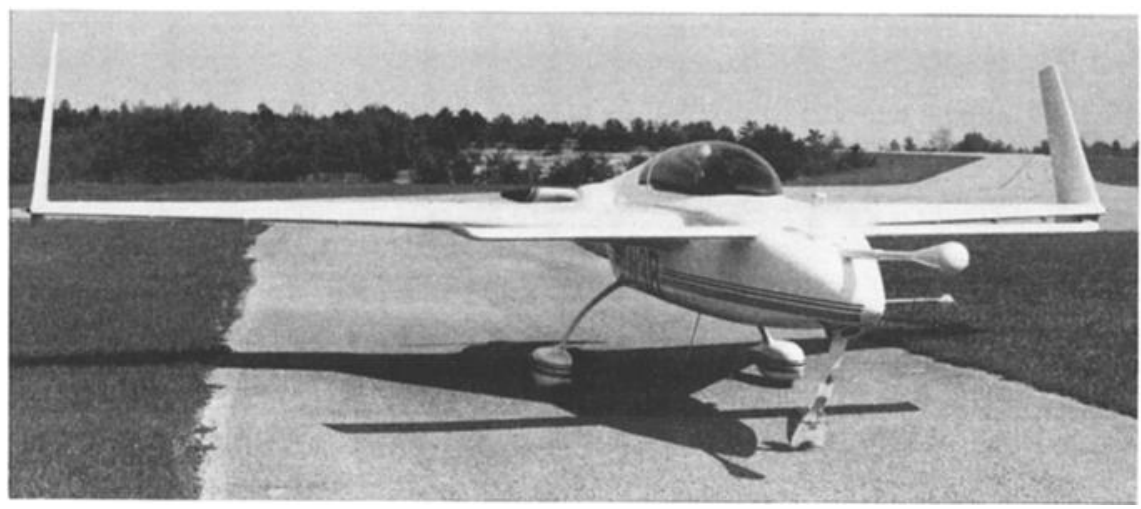

Fig. 1. The Long-EZ airplane with fast response turbulence probe and flux sensors.

tion, both still required booms of appropriate length to reach into undisturbed flow.

In contrast to terrestrial boundary layers, measurement of air-sea exchange is difficult because of the fine turbulent scales and small velocity and concentration fluctuations characteristic of marine boundary layers. Measurement by an aircraft compounds these problems by further compressing the turbulent time scales and amplifying any flow distortion. The Long-EZ airplane (Figure 1) selected for use in these experiments minimizes these difficulties by using sensitive, high-frequency velocity and concentration sensors in a relatively low-speed and low-flow distortion installation. The small canard front wing combined with the "pusher" configuration leaves the front of the aircraft free of propeller disturbance, engine vibration, and exhaust. The nose region of the small, light weight, laminar flow airframe has minimal flow disturbance. Flying at $50 \mathrm{~m} \mathrm{~s}^{-1}$ reduces dynamic compressibility disturbance to one fourth of that typical of high-powered, multiengine airplanes flying at twice that speed [Wyngaard, 1988a, b]. Further, slow speed sampling at low altitudes (transects as low as $10 \mathrm{~m}$ were made) is safe since the aircraft cannot stall and carries a ballistically deployed recovery parachute.

The boat (Figure 2) was a 7.3-m pontoon boat with a beam of $2.4 \mathrm{~m}$. The MFP support package was set on the deck. The probe assembly was mounted on a $1.5-\mathrm{m}$ boom atop a $6-\mathrm{m}$ telescoping mast. The boom-mast assembly was guyed to the four corners of the boat to form a semirigid extension. The sensor head was mounted on the 6-m vertical mast rather than on a horizontal boom to ensure location in a region of low-flow distortion. Although this position minimized flow distortion, it amplified sensor motion in proportion to mast length. As a result, motion of the sensor head during even moderate seas was severe (in 1-m seas, the $\pm 2-G$ rollinduced accelerations drove $v_{p}$ to exceed $\pm 2.5 \mathrm{~m} \mathrm{~s}^{-1}$ ), providing an extreme test of the MFP system.

For data acquisition both MFP systems used 8086 microprocessors with a 44-MB removable 5.25-inch disk cartridge and a 32 channel analog-to-digital converter. The faster airborne MFP collected data at $40 \mathrm{~Hz}$, while the slower boat system collected data at $20 \mathrm{~Hz}$. All fast response analog signals were low-passed with $10-\mathrm{Hz}$ antialiasing filters before analog to digital (A/D) conversion.

\subsection{Evaluation of Motion Removal Techniques}

As indicated by (2), wind measurement from a moving platform is conceptually simple. Further, collocating the accel- erometers with the $\mathbf{V}_{\mathrm{a}}$ sensor simplifies the physics by centering the coordinate system at the $\mathbf{V}_{\mathrm{a}}$ sensor. This simplifies the mathematical framework and reduces measurement and processing demands, since tangential and centripetal accelerations are directly observed. Because sensor motion is directly measured, the nature and motion of the platform are of little consequence. However, the detail of calibrating, installing, and testing numerous sensors must be exact since the data reduction process uses many sensor inputs ( 9 to 10 for $V_{p}$ and 6 to 8 for $\mathbf{V}_{\mathrm{a}}$ ) in a nonlinear, synthesizing process with little tolerance to imposed errors. Any amplitude or phase errors in the signals associated with either the $\mathbf{v}_{\mathbf{a}}$ or the $\mathbf{v}_{\mathbf{p}}$ vector computation results in a spurious velocity in the $\mathbf{V}$ vector. Also, data reduction requires careful digital mixing of high- and lowfrequency contributions from various sensors.

In general, removal of high-frequency, low-amplitude airborne MFP motion was easier than the low-frequency, high-amplitude boat MFP motion. The large pitch and roll boat-motions, coupled with the tall vertical mast, induced fluctuating sensor velocities that were sometimes larger than the corrected wind velocity. Larger ships and shorter booms reduce induced $\mathbf{v}_{\mathrm{p}}$ motion but with the potentially more

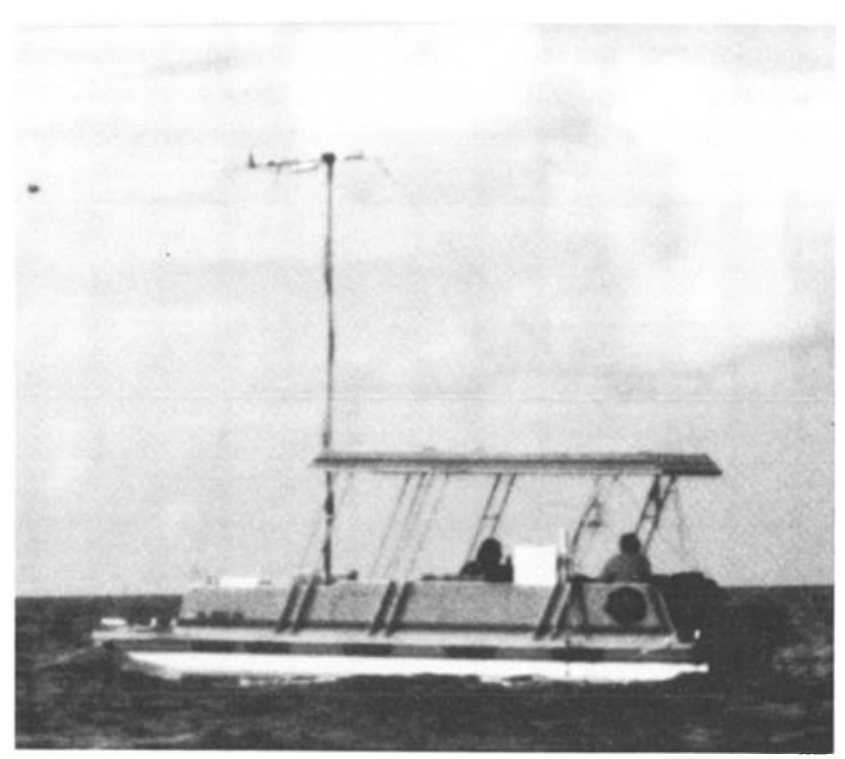

Fig. 2. The pontoon boat, with sonic anemometer and flux sensors atop the 6-m vertical mast. 
serious risk of adding unknown flow distortion to the $\mathrm{V}_{\mathrm{a}}$ vector.

To test the data reduction software, a program was written to simulate rotation and translation about the platform's three axes. The simulation produced data such as would be observed with perfect instruments and data acquisition. Simulation tests included individual and combined motions of pitch, roll, yaw, wave swell, boat translation, and external winds, each having different frequencies and amplitudes. Although the individually synthesized motions were sinusoidal, superimposed motion from the $6^{\circ}$ of freedom, each with different frequencies and amplitudes produced a very demanding composite motion. The data reduction algorithm was generally, though not universally, successful in removing induced velocities. Velocity contamination was insignificant for any single motion source. However, it approached $6 \%$ of the induced velocity when all motions were simultaneously superimposed at typical frequencies and amplitudes. High-frequency contamination was traced to phase shifts in the Blanchard [1971] causal integration scheme. Lowfrequency contamination came from the limited digital accuracy of the simulated LORAN position. Symmetrical integration schemes, presently under development, and the use of a differential global positioning system [Dobosy and Crawford, 1992] will eliminate these errors in future efforts.

To assess the importance of the boat motion contamination, a scalar covariance (i.e., $\overline{\left.(\rho w)^{\prime} s^{\prime}\right)}$ of known magnitude was also introduced. Simulations showed no effect of the $w^{\prime}$ contamination on the synthetic scalar flux due to the inherent lack of correlation. However, for the momentum flux, both $u^{\prime}$ and $v^{\prime}$ contained errors which were weakly correlated with $w^{\prime}$ itself. For typical motion amplitude and frequency of this experiment, the motion contamination generated an artificial $0.05 \mathrm{~m} \mathrm{~s}^{-1}$ shear stress velocity. This error magnitude was independent of ambient winds but scaled with the amplitude of simulated boat motion.

Airplane maneuvers [Bögel and Baumann, 1991] were used to test and calibrate the airborne MFP. For extreme induced motions $\left( \pm 10 \mathrm{~m} \mathrm{~s}^{-1}\right.$ vertical velocities were induced by +2 to $0 \mathrm{G}$ values), $\mathbf{v}_{\mathrm{a}}$ contamination was less than $5 \%$. For induced motions of $\pm 5 \mathrm{~m} \mathrm{~s}^{-1}, \mathrm{~V}_{\mathrm{a}}$ contamination was less than $2 \%$. Along a typical transect the probe vertical velocity standard deviation was typically less than $0.4 \mathrm{~m}$ $\mathrm{s}^{-1}$. This small standard deviation was obtained by use of the aircraft autopilot, which maintained constant altitude and highly colinear transects.

Simultaneous power spectra of the vertical velocity from the pontoon boat and tower flux system (Figure 3) showed agreement between the two systems but with a small $\mathbf{w}^{\prime}$ contamination induced by both wave swell and the boat's high- and low-frequency motion. Velocity variance generated by wave swell was real, but that introduced by boat motions was artificial contamination. A small $w^{\prime}$ contamination was apparent near the boat's $0.55-\mathrm{Hz}$ pitch and $0.66-\mathrm{Hz}$ roll frequencies. However, this contamination was superimposed on a wave swell-induced velocity caused by the coupling of vertical winds to the waves.

Examination of the boat $L E$ cospectrum (not shown) indicated an additional but small contribution to the flux at low frequencies. Simultaneous power spectra from the tower and the Long-EZ lacked this low-frequency contribution. This may have been induced by the unresolved lowfrequency position drift. To remove this artificial low-

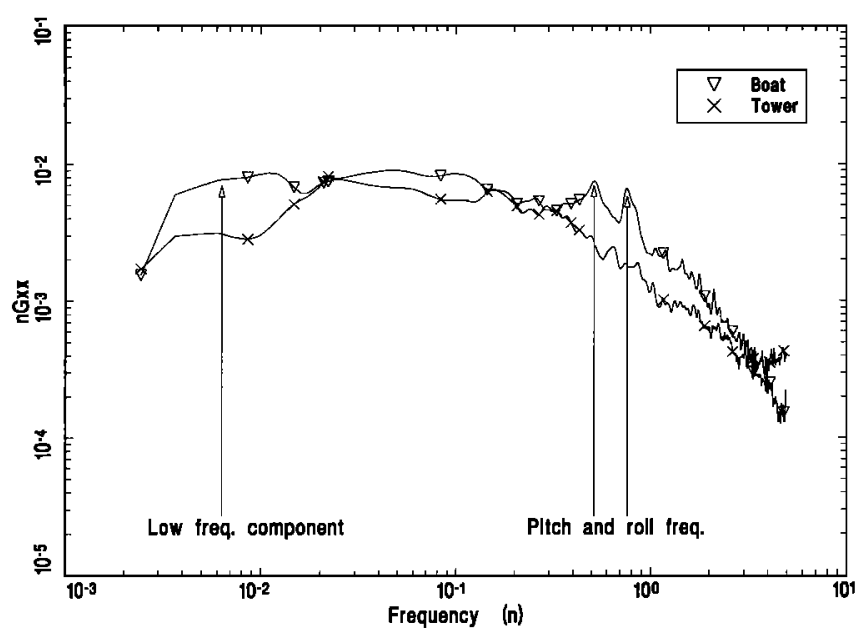

Fig. 3. Comparison of simultaneous boat and tower vertical velocity power spectra.

frequency component, raw data were high-pass filtered, using a 100-s digital recursive filter. Covariances calculated without the high-pass filtering were $10-25 \%$ larger.

The two mobile systems also measured the air-sea exchange of ozone as a means of quality control. Since ozone has low solubility in water, its deposition is limited by surface uptake resistance. This resistance ranges from 10 to $50 \mathrm{~s} \mathrm{~cm}^{-1}$ depending on dissolved compounds within any surface films on the water. Because of this high surface resistance, $\mathrm{O}_{3}$ deposition to water is small and demanding to measure. From the boat the observed half-hour average deposition velocity was typically $0.025 \mathrm{~cm} \mathrm{~s}^{-1}$ with little variation between half-hour observations [see McMillen and Crawford, 1991]. The aircraft and boat $\mathrm{O}_{3}$ flux data were typically within $20 \%$ [see Crawford and McMillen, 1991] and are consistent with measurements reported by Wesely et al. [1981].

\subsection{Measurement of $\Delta p \mathrm{CO}_{2}$}

Herein, $\Delta p \mathrm{CO}_{2}$ is defined as the difference between the partial pressure of $\mathrm{CO}_{2}$ in the ocean $\left(p \mathrm{CO}_{2}\right)$ and in the atmosphere. In the ocean, $p \mathrm{CO}_{2}$ was measured directly by sampling equilibrated headspace air in a closed vessel that contained ocean water. (This technique was recommended by W. S. Broecker et al., personal communications, 1990.) The full implementation details are given by Womack and Crawford [1991]. In brief, ocean water was pumped from a depth of $30 \mathrm{~cm}$ to a constant flow equilibrating chamber while headspace air was recirculated. Dried atmospheric and equilibrated headspace air was alternately analyzed with a LI-COR model LI-6262 $\mathrm{CO}_{2} / \mathrm{H}_{2} \mathrm{O}$ analyzer on a 5-min cycle. The $\mathrm{CO}_{2}$ difference between the two air samples defines the $\Delta p \mathrm{CO}_{2}$ to an accuracy better than $\pm 0.2 \mathrm{ppm}$ and with an equilibrium error of less than $1 \%$. Equilibrator temperature differences were typically less than $\pm 0.25^{\circ} \mathrm{C}$, which resulted in less than a $1 \%$ correction to the ocean $p \mathrm{CO}_{2}$ measurement. The $\mathrm{H}_{2} \mathrm{O}$ channel was used to confirm dryer performance and ensure no $\mathrm{H}_{2} \mathrm{O}$ vapor interference. 


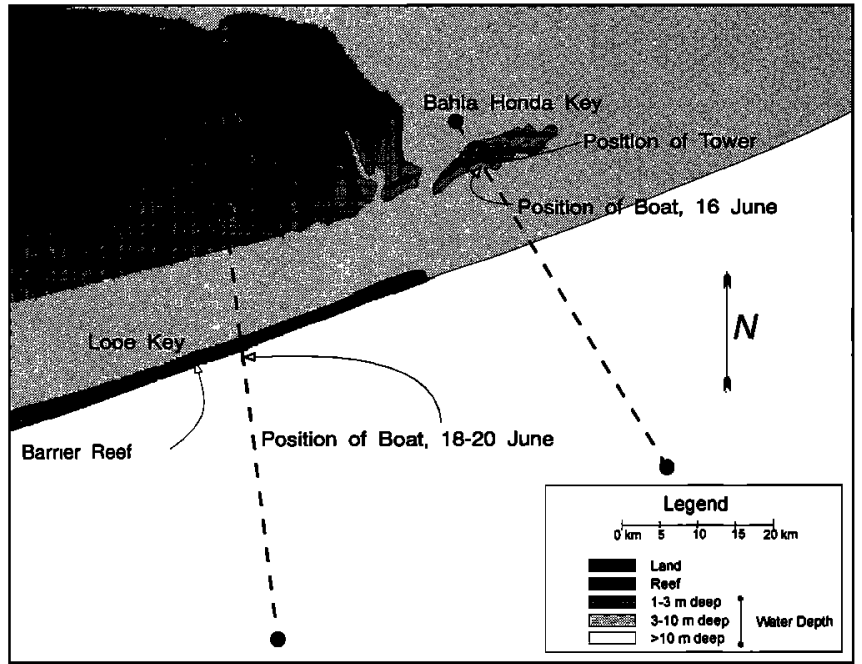

Fig. 4. The research site, showing tower and boat positions and aircraft transects.

\subsection{Site Description and Experimental Design}

The experiment was conducted from June 8 to June 22, 1990 , in the coastal waters of the Florida Keys. Florida's tropical coral reef ecosystem is the most extensive in the continental United States. The interlined "hammockmangrove-sea grass-coral reef" ecosystems create a complicated nutrient cycle and transport system which directly affects the local seawater chemistry. For example, reef calcification removes carbonate ions which depresses alkalinity and shifts the carbonic equilibrium to higher $p \mathrm{CO}_{2}$ concentrations [Berner et al., 1983]. Also, from the Long-EZ it was observed that the sea bottom between the shore and the barrier reef alternates between bare sand and large patches of dense sea grass.

Figure 4 illustrates that the test area was a shallow coastal region near Bahia Honda State Park, located just east of Big Pine Key. The keys in this region are protected by a barrier coral reef 10 to $15 \mathrm{~km}$ offshore. Water depth just inside the reef averages about $10 \mathrm{~m}$. The tower flux system was located at Bahia Honda State Park on the south shore, about $15 \mathrm{~m}$ inland from mean high tide [see Meyers and Baker, 1991]. Flux measurements from the boat were made inside and outside the reef. Long-EZ flux measurements were along the illustrated transects which ran from shore to $40 \mathrm{~km}$ out to sea.

The general design philosophy of the MFP system allows data sampling from the boat while it is anchored, drifting, or under way. However, the boat's slow cruise speed allowed observed spatial trends to be contaminated with temporal trends. Due to this space-time mixing, neither spatial nor time trends were faithfully represented when the boat was moving. For this reason, only data taken while the boat was anchored are presented here. In contrast, the fast moving Long-EZ easily resolved spatial variability. However, it was difficult to keep the airplane airborne long enough to observe time trends. As a result the boat and airplane were viewed as complementary tools, since both space and time trends are important.

The results and related discussion concern data collected during two separate experimental periods, the first lasting 24 hours and the second 48 hours. The first experiment began at local noon on June 16 and the second at 1900 LST on June 17. During the first experiment, the flux systems were collocated to evaluate the fluxes in a nearshore environment. The boat was anchored in $10 \mathrm{~m}$ of water, $500 \mathrm{~m}$ upwind of the shore-based tower. As illustrated by Figure 4, the aircraft transect started $2 \mathrm{~km}$ north of Big Pine Key over the shallow Gulf waters, crossed over the tower, then over the boat, and then extended $30 \mathrm{~km}$ out to sea. The aircraft-observed boundary layer profiles placed the mixed layer depth on June 16 at $1100 \mathrm{~m}$.

The second experiment was designed to explore temporal and spatial variability away from the nearshore influence. The boat was anchored $13.5 \mathrm{~km}$ offshore at NOAA's Looe Key National Marine Sanctuary. This anchorage was $100 \mathrm{~m}$ outside the barrier reef in $25 \mathrm{~m}$ of water. From this anchorage the ocean floor dropped rapidly away to seaward but rose to within $1 \mathrm{~m}$ of the surface at the reef. In general, currents were parallel to the reef, with strong tides overrunning the reef. During the 48-hour experiment, the aircraft flux transects started over shallow, nearshore waters (i.e., the transect did not cross over land), crossed over the boat location, and then continued $40 \mathrm{~km}$ out to sea. The aircraftobserved boundary layer profiles placed the mixed layer depth at only $400 \mathrm{~m}$ on June 18 .

To allow measurement intercomparison and exploration of nearshore spatial variability, multiple transect pairs were flown at a $50 \mathrm{~m} \mathrm{~s}^{-1}$ flight speed at altitudes between 10 and $20 \mathrm{~m}$. Each transect pair consisted of a transect out 30 to 40 $\mathrm{km}$ over the ocean, followed by a return transect back over the shallow coastal zone. The results presented are an average of these transect pairs, which required typically 25 min for completion. The transect pair results are based on classical covariance computations. With the exception of heat flux the graphically displayed transect spatial variability was obtained from a $3-\mathbf{k m}$ symmetrical running covariance computation with output at each kilometer. Therefore each discrete data point represents the average of two 60-s covariance computations. This short covariance is necessary to resolve the variability of the coastal environment. However, a 3-km covariance "window" is short and can increase the variance. In general, the 1-km covariance heat flux data presented were well determined with $0.75 \mathrm{~W} \mathrm{~m}^{-2}$ standard deviation. In contrast the $3-\mathrm{km} \mathrm{CO}_{2}$ flux had a greater spatial variation and varied more temporally.

\section{Results}

\subsection{Temporal Variability of Fluxes}

The left side of Figure 5 illustrates the time series of mean quantities and fluxes measured during the first experiment. The solid curve represents boat data and the dashed curve tower data. Both have been smoothed with a 5-point symmetrical filter. The right half presents the same variables but for the second experiment. Here, symbols present the discrete $\mathbf{3 0}$ minimum average boat data; the solid curve is a smoothed representation. Even though only 72 hours of data are presented, large changes are apparent.

During the first experiment, the boat and tower sensible and latent heat flux densities (Figure $5 f$ ) agreed exceptionally well after $1500 \mathrm{LST}$, with only a $14 \%$ and $4 \%$ mean difference between the observed $H$ and the $L E$, respec- 


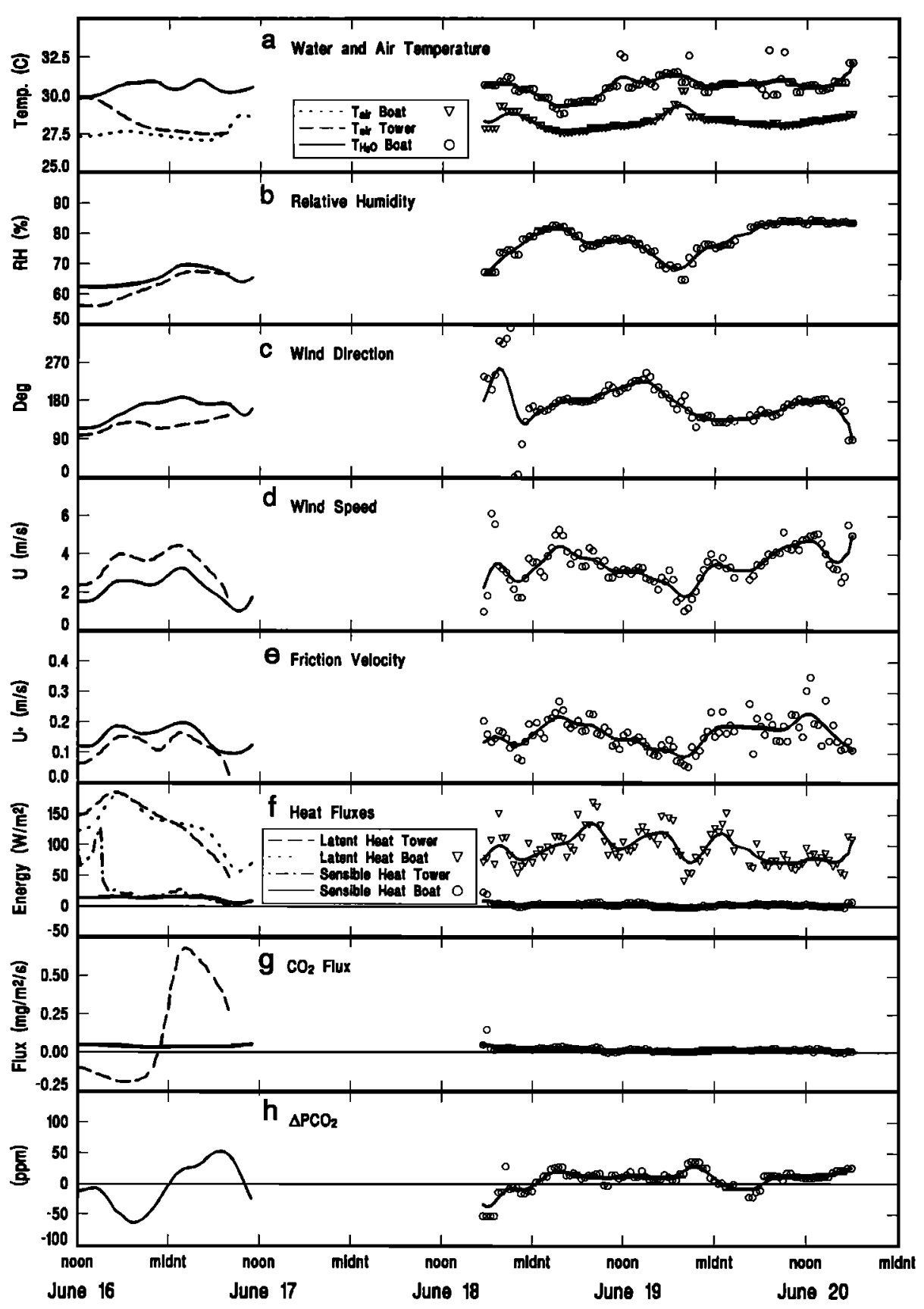

Fig. 5. Meteorological parameters and fluxes observed from the boat and tower during the first and second experiments. For the shorter first experiment, the solid and dashed curves represent smoothed boat and tower data, respectively. For the longer second experiment, the symbols represent 30-min boat observations, and the solid curve is a 5-point smoothed representation.

tively. The standard deviation of the difference between the boat and the tower heat flux was only $3.9 \mathrm{~W} \mathrm{~m}^{-2}$. The $L E$ slowly decreased from $200 \mathrm{~W} \mathrm{~m}^{-2}$ near the start around 1800 LT to about $120 \mathrm{~W} \mathrm{~m}^{-2}$ early on June 17 . This was followed by a sharp drop to $70 \mathrm{~W} \mathrm{~m}^{-2}$ by the end of the experiment. These decreases were due to decreasing air-sea vapor pressure deficit and turbulence. Figure $5 a$ shows a $1^{\circ} \mathrm{C}$ water temperature decrease during this time period, which represents a 2-mbar decrease in the sea surface saturation vapor pressure. At the same time, the wind speed changed little during the middle of the experiment but decreased from 4 to $1 \mathrm{~m} \mathrm{~s}^{-1}$ (Figure $5 d$ ) from the morning of June 17 to the experiment end. The corresponding reduction in mechanical turbulence is illustrated by Figure $5 e$. The air vapor pressure, as illustrated by the Figure $5 b$ relative humidity plot, continually increased during the experiment, further reducing the air-sea vapor pressure deficit.

In general, the sensible heat fluxes measured at the tower and boat systems were in excellent agreement after about $1500 \mathrm{LT}$, even though the magnitudes were quite low $(<20$ $\mathrm{W} \mathrm{m} \mathrm{m}^{-2}$ ). Before $1500 \mathrm{LST}$, much higher fluxes were measured by the tower. This was due to the wind blowing parallel to the coastline, which positioned the tower's measurement footprint partially on the hot sandy beach and 
partially on the warm shallow waters. From the results of Leclerc and Thurtell [1990], and assuming a surface roughness of $z_{0}=0.0006 \mathrm{~m}$ and a measurement height of $10 \mathrm{~m}$, the estimated peak flux contribution is about $200 \mathrm{~m}$ upwind of the tower for neutral conditions. Because the flux footprint would lie closer than $200 \mathrm{~m}$ for lapse conditions, the flux instruments on the tower would "see" more air parcels affected by the warm water close to shore. After 1500 LT the winds shifted perpendicular to the coastline. Following this wind shift, heat fluxes observed from the tower and boat systems were of the order of $20 \mathrm{~W} \mathrm{~m}^{-2}$ and were in good agreement. This wind shift was also apparent in the air temperature decrease and relative humidity (R.H.) increase observed at the tower (Figure $5 a$ and $5 b$ ). The $10 \mathrm{~W} \mathrm{~m}^{-2}$ heat flux decrease toward the experiment end was largely due to the wind speed decrease.

The momentum fluxes (Figure $5 e$ ), as indicated by the friction velocity $\left(u_{*}\right)$, were in good overall agreement, although more variable than either $H$ or $L E$. At the beginning of the period, $u_{*}$ was about $0.2 \mathrm{~m} \mathrm{~s}^{-1}$ with the mean wind speeds averaging near $4 \mathrm{~m} \mathrm{~s}^{-1}$. As the wind speed slowly decreased to less than $1 \mathrm{~m} \mathrm{~s}^{-1}$ near the experiment's end, the corresponding $u_{*}$ values were near $0.05 \mathrm{~m} \mathrm{~s}^{-1}$. The $u_{*}$ boat to tower comparison is good, considering the large variability associated with the momentum flux measurements in comparison to scalar fluxes. The mean drag coefficient $\left(C_{d}\right)$ and its standard error from the tower system was

$$
C_{d}=\frac{-\overline{u^{\prime} w^{\prime}}}{\bar{u}^{2}}=(1.75 \pm 0.10) \times 10^{-3}
$$

This value is nearly identical to that obtained by Smith et al. [1991] from tower measurements in a nearshore setting. Further, aerodynamic deflection of the winds over the Big Pine Key induced a $6.5^{\circ} \pm 1.6^{\circ}$ mean wind vector tilt to the vertical at the tower location. This also is similar to the results obtained by Smith et al. [1991]. The acceleration over the key along with the higher measurement height of the tower would increase the wind speed as illustrated. Finally, the average boat to tower $u_{*}$ difference is $0.05 \mathrm{~m} \mathrm{~s}^{-1}$, which agrees with our $u_{*}$-assessed boat motion contamination. Because atmospheric measurements of air temperature and vapor pressure did not have the high accuracy needed for ocean-atmosphere gradients, transfer coefficients for sensible and latent heat fluxes were not determined.

The $\mathrm{CO}_{2}$ flux comparison (Figure $5 \mathrm{~g}$ ) between the tower and the boat showed large differences in both trend and magnitude. The boat $\mathrm{CO}_{2}$ fluxes were consistently positive, averaging $0.04 \mathrm{mg} \mathrm{m}^{-2} \mathrm{~s}^{-1}$. The tower $\mathrm{CO}_{2}$ fluxes varied with time, changing from -0.2 to nearly $0.75 \mathrm{mg} \mathrm{m}^{-2} \mathrm{~s}^{-1}$. While the boat $\mathrm{CO}_{2}$ fluxes correlate poorly with the $\Delta p \mathrm{CO}_{2}$ measurements made on the boat, the tower fluxes correlate well with $\Delta p \mathrm{CO}_{2}$ in both sign and magnitude.

These differences appear real and illustrate strong nearshore spatial and temporal gradients in the physical, chemical, and biological processes driving $\mathrm{CO}_{2}$ air-sea exchange. The tower footprint included the boat position and hence should have yielded $\mathrm{CO}_{2}$ fluxes that were consistent with the observed $\triangle p \mathrm{CO}_{2}$. However, the boat's flux "footprint" was farther upwind, more distant from shore, and over deeper, relatively cooler water. The sharp nature of the spatial gradients was further supported by the airborne flux and concentration transects and the rapid $\Delta p \mathrm{CO}_{2}$ changes. The

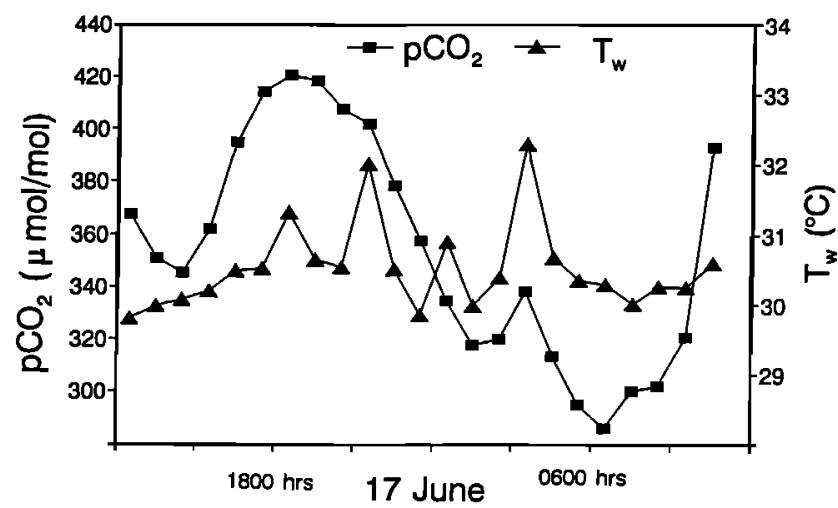

Fig. 6. Ocean $p \mathrm{CO}_{2}$ and temperature as a function of time.

$\Delta p \mathrm{CO}_{2}$ values measured on the boat, when operating close to the shore, change from -50 to nearly +90 ppm in less than 12 hours. The time trends and magnitudes were much less during the second run in the more open ocean setting. Ocean currents were not measured but were observed to be strong and generally along the coast. Since the winds were seldom parallel to the coast, the $\Delta p \mathrm{CO}_{2}$ measurements were not necessarily representative of the area generating the fluxes observed by the boat. Further, it is speculated that there were large horizontal $\Delta p \mathrm{CO}_{2}$ gradients, especially perpendicular to the coast. Smith and Jones [1985], using the potentiometric acid titration method, found $\Delta p \mathrm{CO}_{2}$ values ranging from about 43 to $58 \mathrm{ppm}$. These observations were challenged by Broecker et al. [1986] as "systematically overestimated by as much as $50 \mathrm{ppm}$." The $\Delta p \mathrm{CO}_{2}$ values reported here were obtained with a recirculating equilibrator similar in approach to that described by Kanwisher [1960] and support the large $\Delta p \mathrm{CO}_{2}$ observations of Smith and Jones [1985].

The measured $p \mathrm{CO}_{2}$ values show some correlation with water temperature, as illustrated in Figure 6. Some of the largely positive $\Delta p \mathrm{CO}_{2}$ observations during both the first and the second runs occurred at times when that water temperature was increasing. The $p \mathrm{CO}_{2}$ to temperature correlation suggests the water temperature was changing faster than $p \mathrm{CO}_{2}$ equilibrium solubility could be established. The $\Delta p \mathrm{CO}_{2}$ also depends on salinity, however, salinity measurements were not made as part of this experiment. Sea surface temperature, as indicated by airborne infrared temperature measurements (Figure 7e), showed about a $4^{\circ} \mathrm{C}$ change in the nearshore environment. Considering the $50 \mathrm{~ms}^{-1}$ transit speed, the sharp gradients observed, and the 1-km spatial average plotted, the magnitude of the temperature gradient is probably underestimated. These strong nearshore temperature gradients and the indication of a positive $p \mathrm{CO}_{2}$ temperature correlation support the hypothesis of a large $\mathrm{CO}_{2}$ flux gradient. It is believed that a sharp nearshore $\mathrm{CO}_{2}$ flux gradient existed and when combined with nearshore wave activity explains the difference observed in $\mathrm{CO}_{2}$ flux measurements between the boat and the tower systems.

The latent heat flux time series collected from the boat during the second experiment shows some temporal variability (Figure 5, right side), even though the boat was $13.5 \mathrm{~km}$ from shore. The sensible heat and $\mathrm{CO}_{2}$ fluxes were remarkably constant, with only about a $10 \%$ variation in the half-hour runs. The boat-observed $\mathrm{CO}_{2}$ fluxes during the second experiment were somewhat smaller and usually 

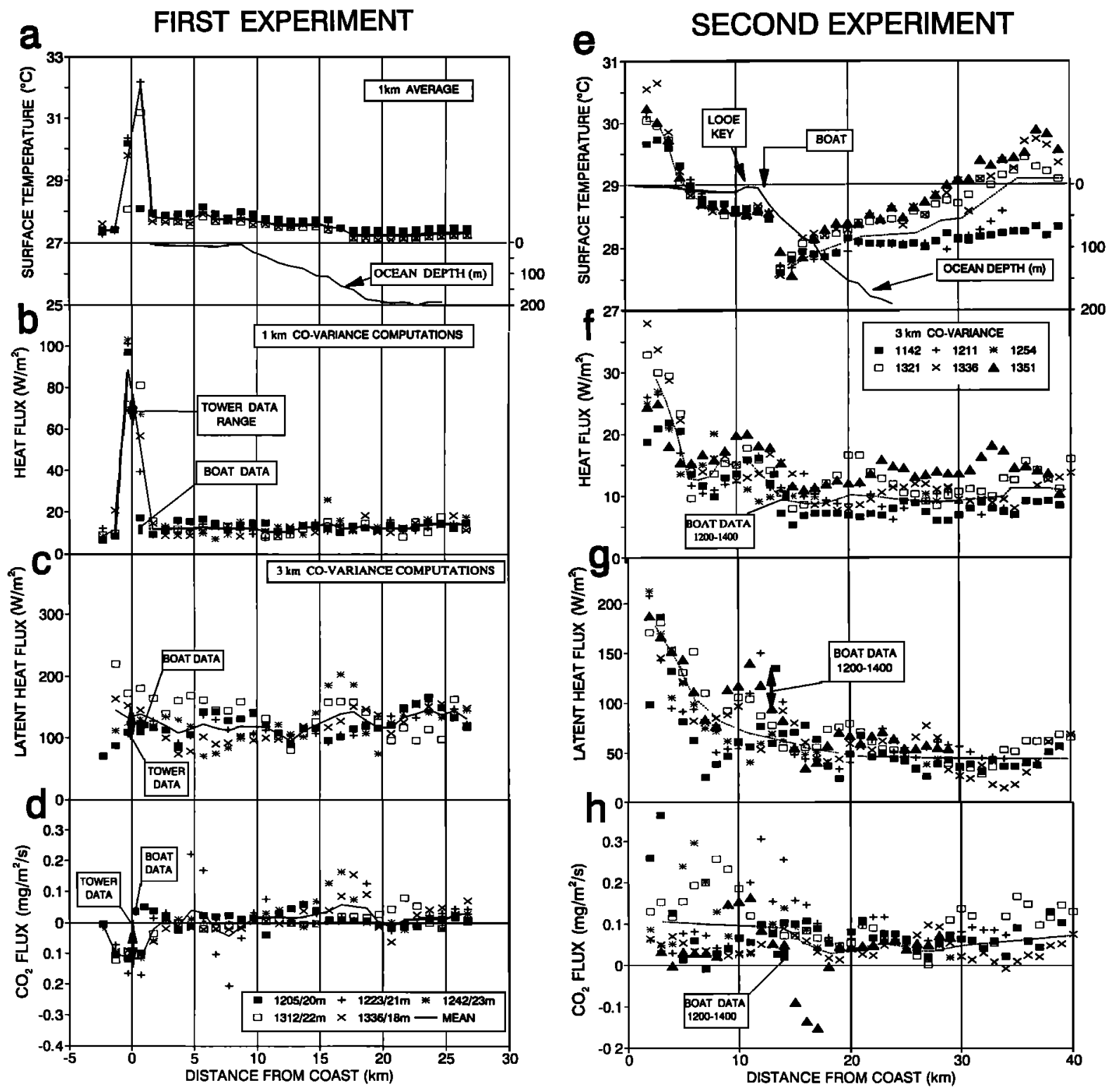

Fig. 7. (a) and (e) Surface temperature, $(b)$ and $(f)$ heat flux, $(c)$ and $(g)$ moisture flux, and $(d)$ and $(h) \mathrm{CO}_{2}$ flux observed from the Long-EZ during the 24- (left side) and 48- (right side) hour experiments.

positive. The $\mathrm{CO}_{2}$ flux averaged $0.019 \mathrm{mg} \mathrm{m}^{-2} \mathrm{~s}^{-1}$ and displayed less temporal variation than during the 24-hour period. The average $\Delta p \mathrm{CO}_{2}$ was $9.2 \mathrm{ppm}$, which yielded an average transfer velocity (flux divided by the concentration difference across the sublayer) of $0.12 \mathrm{~cm} \mathrm{~s}^{-1}$. This value is consistent with the transfer velocities found by Wesely et al. [1982] for similar wind conditions. Although the boat was anchored over the reef and currents interacting with the reef were likely a factor, the boat and airplane data agreed well during both experiments, with both showing more shortterm variance in the flux data from the second experiment.

\subsection{Spatial Variability of Fluxes}

The driving potentials for heat, moisture, and $\mathrm{CO}_{2}$ exchange are the air-sea temperature and $p \mathrm{CO}_{2}$ differences. Any spatial variance in these differences should correlate with the associated flux. The surface temperature (Figure
$7 a$ ), which also controls surface vapor pressure, was measured by an infrared surface temperature sensor on the aircraft. The most notable feature is the spatially sharp $\approx 4^{\circ} \mathrm{C}$ "hot spot" associated with the island and nearby shallow water during both experiments. Along the transect of June 16 , Big Pine Key is about $1 \mathrm{~km}$ wide and is bordered by the Gulf to the north and the Atlantic to the south. The waterland-water transition is apparent. In addition, there is a small but persistent deep ocean temperature discontinuity at 17 km. An ocean current discontinuity, such as coastal upwelling, would be necessary to maintain this persistent temperature discontinuity.

The large, nearshore peak in sensible heat flux (Figure 7b) is expected, considering the observed surface temperature. The 1-km covariance presented is necessary to resolve this sharp peak; it is acknowledged that a longer path-average is necessary to derive accurate flux estimates. Both the boat 
and the tower $\boldsymbol{H}$ measurements supported the spatial trend and agree in magnitude with the airplane-observed $\boldsymbol{H}$.

The latent heat flux (Figure 7c) showed more variance and less spatial variability than $\boldsymbol{H}$. Spectral covariance analysis showed that relative to temperature, both $\mathrm{H}_{2} \mathrm{O}$ and $\mathrm{CO}_{2}$ were associated with more temporal variability. Although this explains the low flux variance, it raises an interesting question as to the source of the temporal variations for $\mathrm{H}_{2} \mathrm{O}$ and $\mathrm{CO}_{2}$ exchange. With the exception of nonstationarity, it is unlikely the difference has an atmospheric basis. It is more likely related to the biological "patchiness" of the ocean in this biologically active region, or to the complex coastal currents. With respect to $L E$ all three systems were in agreement.

The $\mathrm{CO}_{2}$ flux (Figure $7 d$ ) was slightly positive over the open ocean. However, nearshore, the measured $\mathrm{CO}_{2}$ flux gradient was extremely sharp and the flux became negative near the shore and over the flux tower. Again, the three systems are in good agreement, especially considering the large spatial variability in $\mathrm{H}_{2} \mathrm{O}$ and $\mathrm{CO}_{2}$ flux. The observed $\Delta p \mathrm{CO}_{2}$ was in transition during the flights and changed from around $-30 \mathrm{ppm}$ at the beginning to $+10 \mathrm{ppm}$ at the end of the flights. Considering the nearshore complexity of tides, currents, biology, and surface water heating, these $\Delta p \mathrm{CO}_{2}$ observations are not considered representative for the transects. At the boat location the $\Delta p \mathrm{CO}_{2}$ observations support the aircraft observations since both, on average, are negative.

Microscale circulation and coastal upwelling were also factors influencing the observations. As an example, note that both the $\mathrm{H}_{2} \mathrm{O}$ and the $\mathrm{CO}_{2}$ flux observations are different in character at the $17-\mathrm{km}$ minor temperature discontinuity. Finally, the significant land and nearshore $\mathrm{CO}_{2}$ uptake by vegetation, coupled with the oblique to shore wind direction, would have also contributed to the negative tower $\mathrm{CO}_{2}$ flux.

The transect results for the second experiment are displayed on the right side of Figure 7. The measured surface temperature (Figure 7e) indicates a strong coherent spatial and temporal trend. Ocean currents, interacting with the Looe Key Marine Sanctuary reef, caused a $1^{\circ} \mathrm{C}$ surface temperature discontinuity near the boat anchorage. Inland from this discontinuity, heating of shallow water allowed the surface temperature to rise rapidly more than $2^{\circ} \mathrm{C}$ as the shore was approached. Beyond the reef, the deep ocean surface temperature increased with time, probably as the warm Gulf Stream meandered inland during the sampling period.

Figures $7 f, 7 g$, and $7 h$ present the airplane-observed spatial variability from nearshore out to $40 \mathrm{~km}$. The boat's observations, at its $13.5-\mathrm{km}$ anchorage, are also plotted. Beyond $15 \mathrm{~km}$, past the barrier reef location, the open ocean fluxes were spatially but not temporally invariant. However, near the reef and increasingly as the shore was approached, $H$ and $L E$ increased dramatically in response to the warming of the shallow water. Considering the boat's location over the discontinuity and the short covariance of the aircraft observations, the agreement between the boat and the aircraft system was satisfactory.

It is interesting that during the second experiment, $H$ displayed more variance, as did the surface water temperature. Also, the $\boldsymbol{H}$ time trend followed the time trend in the surface temperature. The boat data were somewhat higher for $L E$ relative to the airborne data, but this disagreement was not large, especially in light of the variance in both the observations and the boat's anchorage over the temperature discontinuity.

During the second experiment, $L E$ was about half of that observed during the first. Neither the wind speed, which was low on each day, nor the ocean surface temperature had significantly changed to explain this drop. However, the mixed layer depth $(400 \mathrm{~m})$ had decreased to less than half, and the relative humidity had increased from $61 \%$ to about $75 \%$.

Tides, biological patchiness, and ocean upwelling are other important factors influencing not only the covariances but also the other aspects of the observations. For example, the large $L E$ over the small island generated localized cumulus clouds. On June 19 (but not the 16) these clouds were observed along with a water vapor mixing ratio decrease of $10 \%$ along the $13.5-\mathrm{km}$ path from the boat anchorage to the key. This suggests a circulation cell allowing intrusion of dry air from aloft. The $\mathrm{H}_{2} \mathrm{O}$ vapor trend indicated that the cell boundary was also around the boat anchorage.

The complexity of tidal currents and ocean upwelling is indicated by the sharp discontinuity in surface temperature and the complexity in the time trend of observed $\triangle p \mathrm{CO}_{2}$. During the sampling period the $\Delta p \mathrm{CO}_{2}$ ranged from 10 to 18 ppm. This positive $\Delta p \mathrm{CO}_{2}$ observation supports both the local boat and the aircraft flux measurements. Although the boat $\mathrm{CO}_{2}$ flux measurement appears low, it could be correct; the boat system measured a footprint which extended a few hundred meters upwind, and the airplane observed a lower $\mathrm{CO}_{2}$ flux just upwind of the boat.

\section{Conclusion}

Heat, water vapor, $\mathrm{CO}_{2}$, and momentum air-sea exchange rates were successfully measured from a boat, plane, and tower in a marine environment. The $\mathrm{CO}_{2}$ flux observed from the airplane agreed with the two other systems and showed the expected trends. Transfer velocities for $\mathrm{CO}_{2}$ from the boat system away from shore were of the order of $0.1 \mathrm{~cm}$ $\mathrm{s}^{-1}$. The temporal and spatial variability of $\mathrm{CO}_{2}$ flux was much larger than that of heat flux. The observed temporal and spatial variance illustrates that the coastal zone is not typical of the deep ocean. To understand the dynamics of exchange in the coastal environment will be difficult and will require cooperation between atmospheric and oceanic scientists.

Some recent results support the present finding that airsea exchange rates may be characterized by a spatial and temporal variability that is not yet well appreciated. Watson et al. [1991] report results from open ocean studies that indicate large spatial variability in $\Delta p \mathrm{CO}_{2}$, which was attributed to surface biological factors. Wallace and Wirick [1992] focused on the question of temporal variability; the authors conclude that sudden bursts of rapid exchange occur, especially in strong winds when waves are breaking. The results presented in this paper are possibly influenced by all such factors: the site was biologically very active, surface films of organic origin were probably present, and shallow-water breaking waves could have influenced the fluxes. The present data do not permit a thorough examination of these factors nor even an ordering of their relative importance. It 
is clear, however, that the matter is far from simple and that air-sea exchange within the coastal environment may have large spatial and temporal variability. Therefore conclusions reached from earlier studies neglecting spatial and temporal variability may be in question.

Acknowledgments. This work was supported by the National Oceanic and Atmospheric Administration. The authors thank Billy Causey and other personnel of the Looe Key National Marine Sanctuary for making experimental logistics a joy, which could have been difficult. Special recognition is due David Auble and Jim Womack. David not only supplied his impressive $\mathrm{H}_{2} \mathrm{O} / \mathrm{CO}_{2}$ analyzers but also assisted with the design, construction, and operation of a highly complex collection of instrumentation. Jim designed, built, and operated the $\triangle p \mathrm{CO}_{2}$ analyzer.

\section{REFERENCES}

Asher, W. E., and J. F. Pankow, The effect of surface films on concentration fluctuations close to a gas/liquid surface, paper presented at the Second International Symposium on Air-Water Mass Transfer, pp. 68-80, U.S. Army Eng. Waterways Exp. Stn., Minneapolis, 1990.

Asher, W. E., and J. F. Pankow, Prediction of gas/water mass transport coefficients by a surface renewal model, Environ. Sci. Technol., 25, 1294-1300, 1991.

Auble, D. L., and T. P. Meyers, An open path, fast response infrared absorption gas analyzer for $\mathrm{H}_{2} \mathrm{O}$ and $\mathrm{CO}_{2}$, Boundary Layer Meteorol., 59, 243-256, 1992.

Baldocchi, D. D., B. B. Hicks, and T. P. Meyers, Measuring biosphere-atmosphere exchanges of biologically related gases with micrometeorological methods, Ecology, 69, 1331-1340, 1988.

Berner, R. A., A. C. Lasaga, and R. M. Garrels, The carbonatesilicate geochemical cycle and its effect on atmospheric carbon dioxide over the past 100 million years, Am. J. Sci., 283, 641-683, 1983.

Blanchard, R. L., A new algorithm for computing inertial altitude and vertical velocity, IEEE Trans. Aerosp. Electron. Syst. AES, 7, 1143-1146, 1971.

Bögel, W., and R. Baumann, Test and calibration of the DLR Falcon wind measuring system by maneuvers, J. Atmos. Ocean. Technol., 8, 5-18, 1991.

Bradley, E. F., P. A. Coppin, and J. S. Godfrey, Measurements of sensible and latent heat flux in the western equatorial Pacific ocean, J. Geophys. Res., 96, 3375-3389, 1991.

Broecker, W. S., and T. H. Peng, Tracers in the Sea, 690 pp., Eldigo, Palisades, New York, 1982.

Broecker, W. S., T. Takahashi, H. J. Simpson, and T. H. Peng, Science, 206, 409-415, 1982.

Broecker, W. S., J. R. Ledwell, T. Takahashi, R. Weiss, L. Merlivat, L. Memery, T-H. Peng, B. Jahne, and K. O. Munnich, Isotopic versus micrometeorologic ocean $\mathrm{CO}_{2}$ fluxes: $\mathrm{A}$ serious conflict, J. Geophys. Res., 91, 10,517-10,527, 1986.

Businger, J. A., Evaluation of the accuracy with which dry deposition can be measured with current micrometeorological techniques, J. Clim. Appl. Meteorol., 25, 1100-1124, 1986.

Coppin, P. A., E. F. Bradley, I. J. Barton, and J. S. Godfrey, Simultaneous observations of sea surface temperature in the western equatorial Pacific Ocean by bulk, radiative, and satellite methods, J. Geophys. Res., 96, 3401-3409, 1991.

Crawford, T. L., and R. J. Dobosy, A sensitive fast-response probe to measure turbulence and heat flux from any airplane, Boundary Layer Meteorol., 59, 257-278, 1992.

Crawford, T. L., and R. T. McMillen, Direct measurement of $\mathrm{CO}_{2}$ exchange to the ocean using an airbome eddy-correlation system, in Proceedings of the 7th Conference on Meteorological Observations and Instrumentation, American Meteorological Society, Boston, Mass., 1991.

Crawford, T. L., R. T. McMillen, and R. J. Dobosy, Description of a "generic" mobile flux platform with demonstration on a small airplane, NOAA Tech. Memo. ERL ARL-184, p. 80, Natl. Oceanic and Atmos. Admin., Washington, D. C., 1990.

Crawford, T. L., R. T. McMillen, and R. J. Dobosy, Description of a "generic" mobile flux platform using a small airplane and a pontoon boat, in Proceedings of the 7th AMS Conference on Meteorological Observations and Instrumentation, pp. 37-41, American Meteorological Society, Boston, Mass., 1991.

Deacon, E. L., Gas transfer to and across an air-water interface, Tellus, 29, 363-374, 1977.

Denmead, O. T., Micrometeorological measurements of air-water exchange of $\mathrm{CO}_{2}$, in Proceedings of the Fifth International Conference on Precipitation Scavenging and AtmosphereSurface Exchange Processes, edited by W. G. W. Slinn and S. E. Schwartz, 1991.

Dobosy, R. J., and T. L. Crawford, Simpler wind measurements from moving vehicles using the Global Positioning System (GPS), Proceedings of the 7th AMS Conference on Meteorological Observations and Instrumentation, American Meteorological Society, Boston, Mass., 1992.

Garratt, J. R., Review of drag coefficients over oceans and continents, Mon. Weather Rev., 105, 915-929, 1977.

Hasse, L., The sea surface temperature deviation and the heat flow at the sea-air interface, Boundary Layer Meteorol., 1, 368-379, 1971.

Hicks, B. B., Some evaluations of drag and bulk transfer coefficients over water bodies of different sizes, Boundary Layer Meteorol., 3 , 201-213, 1972.

Hicks, B. B., A procedure for the formulation of bulk transfer coefficients over water, Boundary Layer Meteorol., 8, 515-524, 1975.

Kaimal, J. C., J. E. Gaynor, H. A. Zimmerman, and G. A. Zimmerman, Minimizing flow distortion errors in a sonic anemometer, Boundary Layer Meteorol., 53, 103-115, 1990.

Kanwisher, $\mathrm{J} ., p \mathrm{CO}_{2}$ in sea water and its effect on the movement of $\mathrm{CO}_{2}$ in nature, Tellus, $12(2), 209-215,1960$.

Leclerc, M. Y., and G. W. Thurtell, Footprint prediction of scalar flux using a Markovian analysis, Boundary Layer Meteorol., 52, 247-258, 1990.

Lenschow, D. H., and B. B. Hicks, Global tropospheric chemistry-Chemical fluxes in the global atmosphere, paper presented at the Workshop on Measurements of Surface Exchange and Flux Divergence of Chemical Species in the Global Atmosphere, Natl. Sci. Found., NASA, NOAA, Columbia Univ., New York, Oct. 1987. (Available from the Univ. Corp. for Atmos. Res., Boulder, Colo.)

Liss, P. S., and L. Merlivat, Air-sea gas exchange rates: Introduction and synthesis, in The Role of Air-Sea Exchange in Geochemical Cycling, edited by P. Buat-Menard, pp. 113-127, D. Reidel, Norwell, Mass., 1986.

McMillen, R. T., and T. L. Crawford, Direct measurement of $\mathrm{CO}_{2}$ exchange to the ocean using a ship mounted eddy-correlation system, in Proceedings of the 7th Conference on Meteorological Observations and Instrumentation, pp. 42-45, American Meteorological Society, Boston, Mass., 1991.

Meyers, T. P., and C. B. Baker, Ocean/atmosphere exchange of momentum, heat, moisture and $\mathrm{CO}_{2}$ in shallow water zones, in Proceedings of the 7th AMS Conference on Meteorological Observations and Instrumentation, American Meteorological Society, Boston, Mass., 1991.

Papadimitrakis, Y. A., Y-H. L. Hsu, and J. Wu, Turbulent heat and mass transfers across a thermally stratified air-water interface, $J$. Geophys. Res., 91, 10,607-10,619, 1986.

Schuepp, P. H., M. Y. Leclerc, J. I. MacPherson, and R. L. Desjardins, Footprint prediction of scalar fluxes from analytical solutions of the diffusion equation, Boundary Layer Meteorol., $50,355-373,1990$.

Slinn, W. G. N., L. Hasse, B. B. Hicks, A. W. Hogan, D. Lal, P. S. Liss, K. O. Munnich, G. A. Sehmel, and O. Vittori, Some aspects of the transfer of atmospheric trace constituents past the air-sea interface, Atmos. Environ., 12, 2055-2087, 1978.

Smith, S. D., Coefficients for sea surface wind stress, heat flux, and wind profiles as a function of wind speed and temperature, $J$. Geophys. Res., 93, 15,467-15,472, 1988.

Smith, S. D., and E. P. Jones, Evidence for wind-pumping of air-sea exchange based on direct measurements of $\mathrm{CO}_{2}$ fluxes, $\mathrm{J}$. Geophys. Res., 90, 8085-8092, 1985.

Smith, S. D., and E. P. Jones, Isotopic and micrometeorological ocean $\mathrm{CO}_{2}$ fluxes: Different space and time scales, J. Geophys. Res., 91, 10,529-10,532, 1986.

Smith, S. D., R. J. Anderson, E. P. Jones, R. L. Desjardins, R. M. 
Moore, O. Hertzman, and B. D. Johnson, A new measurement of $\mathrm{CO}_{2}$ eddy flux in the near-shore atmospheric surface layer, $J$. Geophys. Res., 96, 8881-8887, 1991.

Toggweiler, J. R., K. Dixon, and K. Bryan, Simulations of radiocarbon in a coarse resolution world ocean model, 1 , Steady state prebomb distributions, J. Geophys. Res., 94, 8217-8242, 1989a.

Toggweiler, J. R., K. Dixon, and K. Bryan, Simulations of radiocarbon in a coarse resolution world ocean model, 2, Distributions of bomb-produced carbon-14, J. Geophys. Res., 94, 8243-8264, $1989 b$.

Tsukamoto, O., E. Ohtaki, H. Ishida, M. Horiguchi, and Y. Mitsuta, On-board direct measurements of turbulent fluxes over the open sea, J. Meteorol. Soc. Jpn., 68, 203-211, 1990.

Wallace, D. W. R., and C. D. Wirick, Large air sea gas fluxes associated with breaking waves, Nature, 356, 694-696, 1992.

Watson, A. J., C. Robinson, J. E. Robinson, P. J. le B. Williams, and M. J. R. Fasham, Spatial variability in the sink for atmospheric carbon dioxide in the North Atlantic, Nature, 350, 50-53, 1991.

Webb, E. K., G. I. Pearman, and R. Leuning, Correction of flux measurements for density effects due to heat and water vapor transfer, Q. J. R. Meteorol. Soc., 106, 85-100, 1980.

Wesely, M. L., Comments on bulk parameterizations of air-sea exchanges of heat and water vapor including the molecular constraints at the surface, J. Atmos. Sci., 37, 2798-2800, 1980.

Wesely, M. L., Response to "Isotopic versus micrometeorologic ocean $\mathrm{CO}_{2}$ fluxes: A serious conflict" by W. Broecker et al., $J$. Geophys. Res., 91, 10,533-10,535, 1986.

Wesely, M. L., D. R. Cook, and R. M. Williams, Field measurements of small ozone fluxes to snow, wet bare soil and lake water, Boundary Layer Meteorol., 20, 459-471, 1981.
Wesely, M. L., D. R. Cook, R. L. Hart, and R. M. Williams, Air-sea exchange of $\mathrm{CO}_{2}$ and evidence for enhanced upward fluxes, $J$. Geophys. Res., 87, 8827-8832, 1982.

Womack, J. D., and T. L. Crawford, Dissolved $\mathrm{CO}_{2}$ concentration observed in the ocean off the Florida Keys, in Proceedings of the 7th AMS Conference on Meteorological Observations and Instrumentation, pp. 34-36, American Meteorological Society, Boston, Mass., 1991.

Wu, J., Wind-stress coefficients over sea surface from breeze to hurricane, J. Geophys. Res., 87, 9704-9706, 1982.

Wu, J., Stability parameters and wind-stress coefficients under various atmospheric conditions, J. Atmos. Oceanic Technol., 3, 333-339, 1986.

Wu, J., Momentum flux from wind to aqueous flows at various wind velocities and fetches, J. Phys. Oceanogr., 18, 140-144, 1988.

Wyngaard, J. C., Flow-distortion effects on scalar flux measurements in the surface layer: Implications for sensor design, Boundary Layer Meteorol., 42, 9-26, $1988 a$.

Wyngaard, J. C., The effects of probe-induced flow distortion on atmospheric turbulence measurements: Extension to scalars, $J$. Atmos. Sci., 45, 3400-3412, 1988 b.

T. L. Crawford, B. B. Hicks, R. T. McMillen, and T. P. Meyers, National Oceanic and Atmospheric Administration, Air Resources Laboratory, Atmospheric Turbulence and Diffusion Division, P.O. Box 2456, Oak Ridge, TN 37831-2456.

(Received October 12, 1992; revised February 16, 1993; accepted March 10, 1993.) 